\title{
Okuldan İşe Geçiş Sorunlarında Bireyselci ve Yapısalcı Yaklaşım Çatışması
}

\author{
Prof. Dr. Mahmut ÖZER \\ Milli Eğitim Bakanlı̆̆1 \\ mahmutozer2002@yahoo.com, ORCID ID: 0000-0001-8722-8670
}

\section{$\ddot{O} \mathbf{z}$}

$\mathrm{Bu}$ çalışmada Helsinki Üniversitesi tarafından yayınlanan ve Kristiina Brunila ve Lisbeth Lundahl'ın editörlüklerini yaptıkları "Youth on the Move: Tendencies and Tensions in Youth Policies and Practices" başlıklı kitabın okuldan iş piyasasına geçişteki sorunlar için bireyselci ve yapısalcı yaklaşımlar bağlamında değerlendirmesi yapılmaktadır.

Anahtar Kelimeler: Beşeri Sermaye, Genç İşsizlik, İş Piyasası, Mesleki Eğitim, Okuldan İşe Geçiş

JEL Sınıflandırması: E24, I20, J21

\section{The Conflict between Individualist vs Structural Approaches for Issues in the Transition from School-to-Work}

\begin{abstract}
This article provides a critical review of a book edited by Kristiina Brunila ve Lisbeth Lundahl titled as "Youth on the Move: Tendencies and Tensions in Youth Policies and Practices" published by Helsinki University Press in the context of individualist vs structural approaches for issues in the transition from school-to-work.

Keywords: Human Capital, Labor Market, Transition from School to Work, Vocational Education and Training, Young Unemployment

JEL Classification: E24, I20, J21
\end{abstract}




\section{Giriş}

Eğitimden işe geçiş tüm ülkelerde en önemli güncel problemlerden birisini oluşturmaktadır. Ülkeler, vatandaşlarının eğitim seviyesini yükseltmeye, mesleki eğitimini güçlendirmeye, özellikle genç işsizlik oranlarını düşürmeye çalışmakta, bu hedefleri gerçekleştirmek için politikalar geliştirmektedir (Brunila ve Lundahl, 2020a; 2020b). Eğitim sistemleri, eğitimde erken terkleri azaltmaya çalıştığı gibi eğitim sonunda gençlerin ileri eğitime (örneğin yükseköğretim) veya iş piyasasına kolay geçiş yapmalarını sağlamaya çalışmaktadır. Öğrenciler, kariyer hedeflerine göre eğitim sistemleri içerisinde ilerlemekte, zorunlu eğitim sonrası ya eğitimlerine devam etmeye çalışmakta ya da istihdam arayışına girmektedir. Bu bağlamda, eğitimde, işte veya stajda olmayan genç nüfus, yani NEET (Not in Employment, Education or Training) verileri bir ülkede sadece eğitim sistemi değil, aynı zamanda iş piyasası ve ekonomisi hakkında da bilgi sağlamaktadır. Ülkeler eğitimden işe geçişi kolaylaştırmak ve böylece NEET oranını düşürebilmek için farklı projeler gerçekleştirmektedir. Özellikle NEET oranını düşürebilmek amacıyla gençleri tekrar eğitime ve işe entegre edebilmek için ciddi yatırımlar yapılmaktadır (Brunila ve Lundahl, 2020; Comission of the European Communities, 2005; Lundahl ve Olofsson, 2014).

Eğitimden işe geçiş sorun alanı ile ilgili tartışmalar ağırlıklı olarak, eğitim sistemlerinin modern toplumun ihtiyacı olan insan kaynaklarını yetiştirmede ne kadar başarılı oldukları etrafında dügümlenmektedir (Darling-Hammond, 2010). Aslında problem alanı iki uzayın kesişiminden oluşmaktadır: Eğitim uzayı ve iş piyasası uzayı. Dolayısıyla alandaki problemlerin çözümü de her iki uzaydaki sorunların birbirleri ile bağlantılı bir şekilde çözümünü gerektirmektedir.

Okuldan işe geçiş ile ilgili tartışmalara yakından bakıldığında çoğu kez iş piyasası uzayındaki sorunların göz ardı edildiği ve ağırlıklı olarak eğitim uzayına odaklanıldığı ve sorunların da çözümlerin de orada arandığı görülmektedir (Lundahl ve Brunila, 2020). Sadece eğitim uzayına odaklanıldığında, eğitimde de sorunlarla ilgili yaygın yaklaşım tüm faktörleri, özellikle okul dışı faktörleri göz ardı etme potansiyeli içerdiği için çok kaynaklı sorunlar bireysel bir soruna indirgenebilmektedir. $\mathrm{Bu}$ durumda da soruna yönelik kapsamlı çözümler üretebilme imkânı ortadan kalkmaktadır. Gerçekte sorunlar hem her iki uzayı hem de geçiş mekanizmalarını kapsayacak şekilde oldukça kapsamlı, karmaşık ve çok-boyutlu olup eğitim ve okul dışı çok sayıda faktörle de ilişkilidir.

$\mathrm{Bu}$ çalışmada eğitimden işe geçişi İskandinav ülkeleri bağlamında ele alan ve Brunila ve Lundhal'ın (2020a) editörlüklerini yaptığı Helsinki Üniversitesi tarafindan yayımlanan 'Hareket Halindeki Gençlik' (Youth on the Move) adlı kitabın değerlendirmesi yapılmaktadır. Değerlendirme, özellikle bu kapsamdaki sorunlara bireyselci ve yapısalcı yaklaşımlar odağında yapılmaktadır. Ayrıca, kitapta tartışılan konular Türkiye'de mesleki ortaöğretim tartışmaları ile de zenginleştirilmektedir. 
The Conflict between Individualist vs Structural

\section{Eğitimde İlerleme ve Okuldan İşe Geçiş}

Kitap sekiz ana bölümden oluşmaktadır. Her bir bölümde eğitim, iş piyasası ve birbirleri arasındaki ilişkiler ve sorunlar o ülke dinamikleri çerçevesinde analiz edilmektedir. Kitap, özellikle farklı ülkelerde saha araştırmaları ve gençlerin görüşlerine de yer verdiği için hem eğitimde ilerleme hem de okuldan iş piyasasına geçiş ile ilgili sorunların farklı boyutlarını ve arkaplanlarını görebilme imkânı vermektedir.

Rönnlund (2020) tarafından hazırlanan birinci bölümde İsveç’te akademik olarak başarılı olan orta sınıfa mensup öğrencilerin okuldan işe geçiş problemleri incelenmektedir. Okuldan işe geçiş çalışmalarında genellikle sosyoekonomik olarak görece daha düşük arkaplana sahip olanların dezavantajları incelenirken bu çalışmada dezavantajlı grup olarak akademik açıdan başarılı öğrencilerin konu edilmesi dikkat çekicidir. İsveç’te, özellikle eğitimde neo-liberal ve ekonomi piyasası temelli ayarlamalar, öğrencilerin iş piyasasında avantajlı olmak ve girişimciliklerini güçlendirmek için eğitimlerini planlayabilen ve eğitim ile iş piyasasındaki şanslarını optimize edebilen bireyler olarak eğitim piyasasında özgürce hareket ettiklerini varsaymaktadır (Rönnlund, 2020). Dolayısıyla İsveç'te eğitim ve iş piyasasına geçiş açısından tüm sorumluluk bireye yüklendiği için soruna yapısal değil bireysel bakıldığı görülmektedir. Birey bu konumlamada artık kendini öncelediği için katılımc1 yaklaşımları da bireysel meselelerle ilgili olmakta, dolayısıyla öz-çıkar kültürü (a culture of self-interest) güçlenmektedir (Ball, 2006; Rönnlund, 2020). Nihayetinde özellikle dezavantajlı arkaplandan gelenlerin bireysel çabaları iyi bir eğitim ve iş piyasasında iyi bir kariyer için yeterli olmamakta; diğer taraftan, avantajlı sosyoekonomik arkaplandan gelen gençler güçlü sosyal, ekonomik ve kültürel kaynaklara erişebildikleri için neo-liberal ve ekonomi piyasası koşullarının beklediği öğrenci-vatandaş rolünü gerçekleştirmede daha az engelle karşılaşmakta, sonuç olarak da okullaşma bir orta-sınıf projesi olmaktadır (Rönnlund, 2020).

Jarvinen (2020) tarafından hazırlanan ikinci bölümde gençlerin sosyal arkaplanı ve iş piyasası kariyerleri arasındaki ilişki Finlandiya örneğinde iki farklı yaş grubu için NEET verileri kullanılarak incelenmektedir. Kapsayıc okul sistemine sahip Finlandiya'da öğrenciler 15 yaşına kadar zorunlu eğitime devam ettikten sonra ya daha ileri eğitime geçiş yapmakta ya da eğitimden çıkmaktadır. Eğitime devam eden öğrenciler için iki seçenek bulunmakta, lise düzeyinde ya akademik ya da mesleki eğitime devam edebilmektedir. Yıllık olarak öğrencilerin yaklaşık \%50'si akademik liselere devam ederken yaklaşık \%40'1 da meslek liselerine devam etmektedir (Jarvinen, 2020). Jarvinen 1980 ve 1990'ların ortasında NEET gruplarının iş piyasasındaki kariyerlerinin sosyal arkaplanları ile ilişkisini araştırırken, hedef grupların pozitif eğitim ve iş piyasası çıktılarını değerlendirmekte, ailelerin eğitimi en açıklayıcı faktör olduğu için, aile eğitim seviyesini sosyal arkaplanın göstergesi olarak kullanmaktadır. İki farklı genç grup arasında sosyal arkaplanın etki derecesi farklı olmasına ve 1990'lardaki grupta bu etkinin düzeyi daha düşük olmasına rağmen, her iki grupta da ailelerin eğitim seviyeleri arttıkça gençlerin 'kararlı' (stable) kariyer grubunda bulunma olasılığı 
artarken, 'durgun' (stagnant) kariyer grubunda yer alan gençlerin büyük bir kısmının ailesinin eğitiminin ise düşük seviyelerde olduğu görülmektedir. Gençlerin sosyoekonomik özelliklerinin eğitim performanslarında ve meslek seçimlerine bağlı olarak kariyer yollarında belirleyici olması küresel bir sorun alanını oluşturmakta ve Türkiye'de de sıklıkla çalışmalara konu olmaktadır (Kuzgun, 2000, 2004; Suna, Tanberkan ve Özer, 2020; Suna ve diğ., 2020). Yapılan çalışmalar, sosyoekonomik özelliklerin öğrencilerin farklı okul türlerine yerleşmesine ve dolayısıyla okul türleri arasında büyük farklar oluşmasına neden olduğunu göstermektedir (Özer, 2020d; Suna, Tanberkan ve Özer, 2020; Suna ve diğ., 2020a, 2020b). Sosyoekonomik özellikler ve akademik başarı arasındaki güçlü ilişki dolayısıyla yüksek sosyoekonomik düzeyden gelen başarılı öğrenciler birlikte eğitim almakta ve bu öğrenci grubunun akademik performansı da artan rekabete dayalı olarak yükselmektedir. Dolayısıyla, bu durum düşük sosyoekonomik düzeydeki öğrencilerin eğitimde yalıtılmasına ve fazladan bir dezavantaj yaşamalarına yol açmaktadır. Bu durum, zaten dezavantajlı bir arkaplandan gelen gençlerin sistemin yapısal özellikleri dolayısıyla daha da zorlanmasına neden olmakta, eğitim ve kariyer tercihlerinde önemli etkiler oluşturmaktadır. Sonuç olarak, iş piyasasına giriş ve kararlı bir kariyere sahip olmak açısından herkes eşit şansa sahip olmamakta, aile eğitim seviyesi gibi okul dışı bir faktörün sadece akademik başarıyı değil, ayrıca iş piyasasındaki kariyeri de etkilemeye devam ettiği görülmektedir. Okullar arasındaki başarı farkının oldukça düşük olduğu ve kapsayıcı eğitimin bu farkı azaltmada büyük bir etkiye sahip olduğu Finlandiya'da bile bu sorunun devam edebiliyor olması, sorunun bireysel değil, daha çok yapısal ve sistemik olduğuna işaret etmektedir.

Arnardottir (2020) tarafından hazırlanan üçüncü bölümde İzlanda'da NEET profili incelenmektedir. İnsanların gençlik yıllarında NEET'de bulunmalarının arkasında farklı sebepler bulunurken yaş ilerledikçe hastalık ve engellilik durumlarının bu gruba dâhil olmada ön plana çıkan faktörler olduğu görülmektedir. İzlanda'da göz önüne alınan NEET grubunun yaklaşı \% 77 'sinin daha önce bir işte çalışması, sorunun bu grupta yer alan insanların iş arama arzusu veya yeteneklerinden ziyade iş piyasasında yeterli iş pozisyonu olmamasından kaynaklandığını ve bireylerin bu nedenle sonunda NEET grubuna girmek durumunda kaldıklarını göstermektedir. Ayrıca, bu grubun daha önce çalıştıkları işlerin ağırlıklı olarak kendilerine zengin kariyer firsatları sunmayan işler olduğu da görülmektedir. Sonuç olarak bu kitap bölümü, İzlanda'da NEET'de bulunmanın gençlerin yetenek eksikliğinden çok iş piyasasındaki sıkıntılardan kaynaklandığı ve iş firsatlarının eksikliğinin ana faktör olduğunu vurgulamaktadır.

Lindblad ve Lundahl (2020) tarafından hazırlanan dördüncü bölümde, İsveç'te göçmen arkaplandan gelen gençlerin eğitim kariyerleri ve okuldan işe geçişleri kapsamlı bir şekilde değerlendirilmektedir. İsveç’te özellikle İsveç dışında doğmuş insanlar için iş piyasasının dezavantajlı olduğu, bu gruptaki insanların işsizlik oranının OECD ülkelerinde en yüksek düzeyde olduğu bilinmektedir (OECD, 2018). Yapılan çalışmada, bu gruptaki gençlerin özellikle ailelerinin oldukça kısıtlı sosyal, ekonomik ve kültürel sermayeleri, dil seviyeleri ve düşük eğitim seviyeleri nedeniyle eğitim kariyerlerinde iş piyasasında tali iş pozisyonları ile ilişkili alanlara yöneldikleri gösterilmektedir. 
Çalışma, bu gruptaki gençlerin aileleri ile okullar arasında iletişimin son derece zayıf olduğunu, ayrıca hem eğitim hem de iş piyasasında 'ötekilik'in (otherness) oldukça belirleyici olduğunu göstermektedir. Çalışma ayrıca, mezun olunmasa bile lisede geçirilen süre arttıkça okul sonrası kariyer fırsatlarının da arttığını ve iş piyasasına geçişin hızlandığını göstermektedir. Örneğin, en az iki yıl lise eğitimi almak bu gruptaki gençlerin NEET'de bulunma riskini görünür bir şekilde azaltmaktadır. Bu nedenle, gençleri eğitimde tutabilmek için geliştirilecek destek mekanizmalarının önemine işaret edilmektedir.

Masoud ve diğerleri (2020) tarafindan hazırlanan beşinci bölümde, Finlandiya'da göçmenlerin entegrasyonu okuldan işe geçiş bağlamında oldukça ayrıntılı bir şekilde ele alınmaktadır. Bu bölüm genel olarak, Finlandiya'da göçmenlerin önceki öğrenmelerinin ve becerilerinin tanınmadığı ve entegrasyon eğitiminin göçmenleri yeni mesleklere yönelmeye zorladığını ve uzun süreli entegrasyon eğitiminin meslek kazandırmanın ötesinde bireylerin Finlandiya yaşam tarzına ve kültürel kodlarına uyuma ağırlık verdiğini, bunun da göçmenler üzerinde travmalara yol açtığını ortaya koymaktadır. Sonuçta, göçmenler 'belirsiz' taleplere cevap verebilmek için sürekli kendilerini geliştirme baskısına maruz kalmaktadır (Masoud ve diğ., 2020; Moore, 2010). Hatta istihdam edilmeseler bile mültecilerden suçu kendilerinde arayarak kendilerini 'istihdam edilebilir nesneler'e dönüştürmek için sürekli çaba göstermeleri beklenmektedir (Moore, 2010). Çalışmada da ortaya konulduğu gibi, göçmenler ülkenin refah sistemine bir yük olarak değerlendirildiği için (Keskinen, 2016), entegrasyon eğitiminin aslında topluma kabul edilmenin gerektirdiği irrasyonel mesleki değişimler de dahil olmak üzere önerilenlerin kabul edildiği bir itaat oluşturma ve topluma ön kabul süreci olarak işlev gördüğü söylenebilir. Bu kapsamda, bir mesleği kendi ülkesinde yıllardır icra eden göçmenlerin bu alanda veya ilişkili alanda meslek sahibi olmalarına izin verilmediği için göçmenlerin başka ülkelere göç etme planları yaptıklarına dair örnekler de sunulmaktadır. Avrupa Birliği’nin İkinci Avrupa Birliği Azınlıklar ve Ayrım Araştırması'na (Second European Union Minorities and Discrimination Survey) göre Finlandiya'nın Avrupa Birliği'ne üye 28 ülke arasında en ayrımcı ülkelerden birisi olduğu (FRA, 2017) göz önüne alındığında bu bölüm sonuçları şaşırtıcı gelmemektedir.

Hodgson ve Spours (2020) tarafından hazırlanan altıncı bölümde İngiltere'de lise sisteminde gençlerin geçiş problemleri farklı dönemlerdeki eğitim politikalarına dayalı olarak ele alınmaktadır. Bölümün odağını savunmasızlar ve yüksek kazanım elde edenlerin arasındaki orta grup oluşturmaktadır. Çalışma, 2010 yılından itibaren hükümet politikalarının özellikle bu orta bölgedeki öğrencileri tehdit ettiğini, bu gruptaki ögrencilerin giderek daha katı bir şekilde tanımlanan ve seçici akademik eğitim ile çok az sunulan yüksek kaliteli çıraklık arasında saçıldıkları belirtmektedir. Sonuçta, durağanlaşan genç iş piyasası da göz önüne alındığında bu grubun eğitim sisteminin yeni 'güvencesizleri' (precariat) olma tehlikesi ile karşı karşıya oldukları vurgulanmaktadır. Anglo-Sakson modelinde minimum devlet düzenlemesi ve işveren gönüllülüğü kültürüne sahip esnek bir iş piyasası olduğu ifade edilmektedir. Hodgson ve Spours (2020), geçişte yaşanan problemlerin ilk bakışta öğrenciler, aileleri veya daha 
geniş anlamda toplum ile ilişkili görünmesine rağmen aslında temel problemin ulusal eğitim politikası ve gençler için daralan iş piyasası ile ilişkili olduğunu ileri sürmektedir.

Brunila ve diğerleri (2020) tarafından hazırlanan yedinci bölümde Finlandiya'da gençlerin geçişlerini yönetmede girişimciliğin ve özellikle eğitime ve işe geçişi yavaşlatan sağlık ve zihinsel rahatsızlık nedeniyle terapötik diskurların birlikte nasıl çalıştıkları incelenmektedir. Burada da genç işsizliğinin bireysel bir problem olarak ele alındığı, sorunun girişimcilik becerileri, tavır ve durum eksikliği ile ilişkilendirildiği, dolayısıyla ekonomik sorunlara terapötik çözümler üretilmeye çalışıldığ gösterilmektedir.

Irisdotter Aldenmyr ve Olson (2020) tarafından hazırlanan sekizinci bölümde ise gençlerin okuldan topluma geçişte öğretmenler tarafından terapötik eğitim desteği almasının önemi ele alınmaktadır. Gençlerin bilgi, beceri ve yetkinliklerinin ötesinde iyi olma hali ve psikolojik sağlamlıklarının da okuldan topluma geçişlerine etki ettiği göz önünde tutularak üç farklı diskur ayrıntılı incelenmektedir: psikolojik risk diskuru, rol model diskuru ve etik diskur. Her üç diskur da İsveç’te hayat yetkinliği eğitimi (life competence education) kapsamında değerlendirilmektedir.

\section{Sorunlara Yapısal Bakmamanın Maliyeti}

Editörlügüüü Brunila ve Lundahl'ın (2020a) yaptı̆̆ı kitapta en dikkat çeken vurgu, dikkate alınan ülkelerde okuldan işe geçiş problemlerinin gençlerin kişisel özellikleriyle açıklanma eğiliminin oldukça yüksek olduğu ve dolayısıyla da tüm başarısızlıklardan gençlerin sorumlu tutulduklarıdır. Bu yaklaşım, aslında kurumsal ve yapısal faktörlerden kaynaklanan sorunların sorumluluğunun da haksız bir şekilde bireylerin üzerine yüklenmesi anlamına gelmektedir. Bir başka deyişle, hangi talihsizliklerle karşılaşırlarsa karşılaşsınlar her şeyin tamamen bireyin kendisinden kaynaklandığı kabul edilmektedir (Diedrich ve Styhre, 2013; Kurki ve diğ., 2018; Masoud ve diğ., 2020). Sorunların kişisel özelliklerle açıklanması çözümün de bireysel düzeyde geliştirilmesini gerektirmektedir (Brunila ve Lundahl, 2020b). Örneğin, aynı kitapta Arnardottir (2020), ailesi İzlanda'da doğmamış olanların çocuklarının NEET'de daha yüksek yüzdede bulunduklarını göstermektedir. Dolayısıyla iş piyasası uzayında bu bağlamda bireyin sorumluluğunun tamamen dışında bir ayrımcılık veya seçiciliğin söz konusu olduğu görülmektedir. Benzer bireyselci yaklaşım eğiliminin İsveç’te de söz konusu olduğu görülmekte, okul başarısızlığının arkasında okul içi ve okul dışı çok sayıda farklı faktör bulunmasına rağmen (Lundahl ve diğ., 2017), yerel karar alıcılar lise terklerinin arkasındaki tek önemli sebebi gençlerin motivasyon eksikliği ile ilişkilendirmektedirler (Lundahl ve Olofsson, 2014). Bu durumda, özellikle lise öğrencilerinin bağımsız ve öz-disipline sahip olması beklendiği için sorunlu öğrencilere yönelik kurumsal rehberlik ve destek hizmetleri giderek azalmaktadır (Lindblad ve Lundahl, 2020). Bu durum, gençlere verilebilecek ikinci şans imkânlarını da ortadan kaldırmaktadır. 
Benzer şekilde Londra, yükseköğretim sonrası iş piyasasına en gecikmeli geçişin yaşandığ 1 tipik bir örnek oluşturmaktadır. Hodgson ve Spours (2020), bu sorunun eğitimin kalitesinden çok Londra'nın finans ve hizmet sektörü ağırlıklı istihdam piyasası yapısıyla ilişkili olduğunu, dolayısıyla Londra'da hem en yüksek mezuniyet oranının hem de mezunlar için en yüksek işsizlik oranının görüldüğünü belirtmektedir. İsveç’te de başlangıç seviyesindeki çoğu işin artık ortadan kalktığı görülmektedir (Lindblad ve Lundahl, 2020). Dolayısıyla, düşük eğitim seviyesine sahip gençler aldıkları eğitimle ilgili bir nitelik sorunu olmamasına rağmen iş piyasasına ilk geçişlerinde zorluklar yaşamakta ve potansiyel NEET grubuna dâhil olmaktadır. Özellikle bu ülkelerde gençlerin eskiden iş piyasalarına ilk geçişte kullandıkları işlerin çoğunun endüstriyel yeniden yapılanma veya işletmelerin düşük insan gücü maliyeti olan ülkelere kaydırılması nedeniyle ortadan kalktığı görülmektedir (Brunila ve Lundahl, 2020b). Sonuç olarak iş piyasaları gençler için daha fazla rekabetçi bir ortam oluşturmaktadir.

Beşeri sermaye kuramı (Becker, 1962; 1964), beşeri bilgi, beceri ve yetkinlikler arttığında iş piyasasında toplamda daha avantajlı olunacağını söylemesine rağmen, herkesin bu becerileri kazanmada eşit olup olmadığı veya eşit olsa bile iş piyasasının herkese eşit davranıp davranmadığı konusu bu kuramın ilgi alanına girmemektedir. Kuramın genel iddiası doğru olmakla birlikte hem eğitim hem de iş piyasasındaki şartlar herkese eşit davranmayı garanti etmemektedir. Örneğin, Finlandiya'da iş piyasasında işverenler göçmen arkaplandan gelenlerin yerine herhangi bir mesleki eğitimi olmayan veya uzun süredir işsiz olan beyaz Finleri tercih etmektedir (Masoud ve diğ., 2020). Dolayısıyla, göçmenlerin istihdam edilmemesi, göçmenlerin bireysel beceri eksikliklerinden ziyade Finlandiya'daki istihdam ve entegrasyon politikalarından kaynaklanmakta ve bu sonucu olarak bireysel değil yapısal bir sorun oluşturmaktadır (Williams, 2009).

Bunun aksine yapısalcı yaklaşımda, genç insanların sosyoekonomik arkaplanlarının yaşamları boyunca bir şekilde önemli olduğu kabul edilmekte ve dezavantajlı durum, sosyal firsatlar eksikliği ile ilişkilendirilmektedir (Jarvinen, 2020). Yapısalcı yaklaşım, sorunun yapısal bir sorun olduğunu kabule imkân verdiği için bu gruba ait gençlere telafi imkânları sunabilmeyi mümkün kılmakta ve bu telafinin eğitim politikaları aracılığıyla gerçekleşmesini sağlayabilmektedir. Diğer taraftan, yapısalcı yaklaşım bireyin başarısızlığının bireyin kendi özelliklerinden kaynaklanmayabileceğini de kabul ettiği için bu kapsamda sunacağı telafi imkânları veya ikinci şans ile aslında sistemin kusurunu telafi etmeye çalıştığ önüne geçmektedir.

Diğer taraftan, eğitimden işe geçişte yaşanan yapısal sorunları anlamada beșeri sermaye kuramının eksikliklerini tamamlama potansiyeli nedeniyle son zamanlarda ağ kuramının (network theory) açıklama potansiyelinden yararlanılmaktadır (Granovetter, 1985). Bu kurama göre, kurumlar ve bireylerin hem kendi içinde hem de birbirleri arasında geliştirilen ve güven tesis eden ilişkiler ağı okuldan işe geçişi doğrudan etkilemektedir (Özer, 2020c; Rosembaum ve diğ., 1990; Zucker, 1986). Dolayısıyla ağ 
kuramı, tek başına bireyin becerileri ve yetkinliklerinin yeterli olmadığını, okuldan işe geçişe etki eden farklı yapılar olduğunu ve bu yapılardan bazılarının ilişkiler ağı ile açıklanabileceğini göstermektedir.

Sonuç olarak sorunların aslında varolan yapılarla da ilişkili olduğu kabul edilmediğinde problemlerin tüm yükü bireyin omuzlarına yüklenmekte ve sistem karşısında birey yalnız bırakılmakta ve değersizleştirilmektedir. Mültecilerin istihdam dışında kalması bile çok sayıda faktörle ilişkili olmasına rağmen kişisel bir eksiklik olarak değerlendirildiği görülmektedir (Masoud ve diğ., 2020). Özellikle göçmen ve azınlık arkaplanlardan gelen gençlerde yüksek oranlarda gerçekleşen okul terkleri ilgili ülkelerde çok görünür olmasına rağmen, sorun çoğunlukla bireyselci yaklaşımla değerlendirildiği için böyle bir sonuca yol açan okul dış1 sosyoekonomik koşullarla ilgili yeterince akademik çalışma yapılmadığı görülmektedir (Lindblad ve Lundahl, 2020; Lundahl ve Lindblad, 2018). Yapısal problemler de böylece farklı ölçeklerde varlığını sürdürmeye devam etmektedir. Bu bağlamda Jarvinen (2020) daha da ileri gitmekte ve dezavantajlı arkaplanlardan gelen gençleri kendi istihdam ve kariyerlerinden sorumlu tutmanın aslında, toplumda sosyal sınıflar arasında eğitim, istihdam ve kariyer firsatları açısından mevcut eşitsizlikleri devam ettirmek anlamına geleceğini iddia etmektedir. Benzer şekilde, mülteciler bağlamında Masoud ve diğerleri (2020) de, sorun bireyde arandığı ve diğer yapısal sorunların çözümlerine odaklanılmadığı için mülteciler için işsizlik ve eşitsizliğin sürdüğünü ifade etmektedir.

Aslında, kitapta bu bağlamda eşitsizliklerin sürdürülebilirliği ile ilgili vurgular Bourdieu (1973) ve Bourdieu ve Passeron (1990) tarafından uzun yıllar önce eğitimin toplumdaki eşitsizliklerin sürdürülmesinde gördüğü işleve yaptıkları vurguyu hatırlatmaktadır. Eğitim sistemlerinin, ülkelerde bu bağlamda mevcut sınıfları hiyerarşik olarak ele alarak ve üst sınıfların kültürel ve sosyal sermayesine daha fazla değer vererek mevcut sistem üzerinden sınıfların konumları ve varlığını sürdürülebilir kıldığı vurgulanmaktadır. Bu işlevin en yalın bir şekilde kendisini hissettirdiği eğitim türünün de mesleki eğitim olduğu görülmektedir (Bernardi ve Ballarino, 2016; Bertocchi ve Spagat, 2004; Bol ve Van de Wefhorst, 2013a; 2013b; Breen ve Jonsson, 2005; Breen, 2005; 2010; Brunello, 2004; Özer ve Perc, 2020; Reichelt ve diğ., 2019).

Kitapta özellikle eğitimden işe geçişteki sorunların çoğu kez eğitimden çok iş piyasası ile ilişkili olduğu, ancak bireyselci yaklaşımla bunun göz ardı edildiği vurgusu, aslında ülkemizde mesleki eğitimde okuldan işe geçiş sorunlarına dair tartışmalarında da sıklıkla karşılaşılan yaklaşım ile benzerlikler göstermektedir. Türkiye'de bu geçişin aslında iş piyasası ile ilişkili sorunlarının yıllardır göz ardı edildiği ve sorunların çoğunlukla mesleki eğitimle ilişkilendirildiği, dolayısıyla da bu geçişin günah keçisi olarak mesleki eğitimin seçildiği görülmektedir (Özer, 2018, 2019a, 2019b, 2020a; Özer ve Suna, 2019, 2020). Bu nedenle mesleki eğitimde çok sayıda iyileştirme yapılmasına rağmen okuldan işe geçişle ilgili tüm sorunlar doğal olarak çözülememekte, diğer taraftan sorunun tamamı eğitim ile ilişkilendirildiği için bu defa da sorunun kaynağ geliştirilen projelerin verimliliğinde aranmakta, dolayısıyla mesleki eğitim kısır döngüye sokulmaktadır (Özer, 2020a, 2020b, 2020c). Bu durum geçişte yaşanan 
sorunlarının kalıcı çözümü için hem eğitim hem de iş piyasası uzaylarındaki sorunların birlikte değerlendirilmesinin önemini bize farklı bağlamda tekrar hatırlatmaktadır.

Diğer taraftan, gençlik araştırmalarının ağırlıklı olarak şehirlerdeki gençlere odaklandığ 1 , bunun da nihayetinde okuldan işe geçiş de dâhil olmak üzere tüm problemlerin sanki bir şehir veya şehirleşme problemi olarak değerlendirme yanılsamasına sevk ettiği görülmektedir (Lundahl ve Brunila, 2020). Aslında bu problemlerin şehir dışında taşra ve kırsalda daha da dramatik olabileceğini göz önüne alarak, buralardaki problemlere yönelik yeni araştırmalar yapılması gerekmektedir. Benzer ihtiyaç Türkiye'de de mesleki eğitim bağlamında söz konusudur. Örneğin, mesleki ve teknik Anadolu Lisesi mezunlarının iş piyasasında istihdam ve iş gücüne katılım oranları yüksek olmasına rağmen eğitim alınan alanla uyumlu iş piyasası pozisyonlarında istihdam oranının düşük olduğu görülmektedir. $\mathrm{Bu}$ sorunun arkaplanında yatan sorunları araştıran bir çalışma, sorunun öncelikle eğitim alınan alanda iş piyasasında yeterince istihdam imkânının bulunmadığını ve ikinci olarak da alan içi ve alan dışı istihdamda yeterli ücret farklılığının oluşmadığını göstermektedir (Suna ve diğ., 2020). Aynı araştırma özellikle farklı illerde ve ilçelerde tekrar edilerek elde edilen bulgularla özellikle bu sorunun kaynaklarının coğrafi olarak nasıl dağıldığını görebilmek ve ona göre planlama yapabilmek mümkün olacaktır.

\section{Sonuç}

Gençlerin hem eğitim hem de iş piyasası ile ilişkileri tüm ülkelerin ana gündemini oluşturmaktadır. Helsinki Üniversitesi tarafından yeni basılan 'Youth on the Move' kitabı ağırlıklı olarak İskandinav ülkelerinde hem eğitim kademeleri arasındaki geçiş hem de eğitimden iş piyasalarına geçişe farklı açılardan değerli ve güncel bir perspektif sağlamaktadır. Kitap özellikle sorunların kaynağının gençlerin kişisel özelliklerine indirgenemeyeceği kadar karmaşık ve çok-boyutlu olduğu vurgusu yapmaktadir.

Eğitimde her kademede devamsızlığı azaltma ve terk oranlarını düşürme, sadece eğitim politikalarını ilgilendiren bir konu olmayıp ayrıca okul terkine ve devamsızlığa yol açabilen okul dışı faktörlerle de mücadele etmeyi ve iyileştirmeler yapmayı gerektirmektedir. Okul başarısızlıklarında öğrenme problemleri, engellilik ve zihinsel rahatsızlıklar ve akademik başarısızlık gibi bireysel seviyede faktörler etkili olduğu gibi (Casillas ve diğ., 2012; Lindblad ve Lundahl, 2020; Myklebust, 2012; Quiroga ve diğ., 2013), ailelerin düşük gelir ve eğitim seviyeleri, aile ve yerleşim yerlerinin dokusu ve komşulukla ilgili problemler, sosyoekonomik kaynakların eksikliği gibi toplumsal faktörler de etkili olabilmektedir (Lindblad ve Lundahl, 2020; Ostergaard ve diğ., 2014; Rumberger, 2011). Özellikle, sorunların erken tespiti ve potansiyel terkler ve başarısızlıklara dair önceden uyarı mekanizmalarının oluşturulması büyük önem arz etmektedir.

Diğer taraftan okul sonrası ileri eğitime devam etme veya iş piyasasına entegrasyon da yine eğitimin her iki alana geçişi ne kadar desteklediği ile ilişkili olduğu gibi eğitim dışı çok sayıda faktörle de ilişkilidir. Bir diğer ifadeyle her iki sorun da çok 
disiplinli bakışı gerektirmektedir. Eğitim ve iş piyasası ile ilgili sorunlar hem kendi uzayları içindeki hem de dışındaki çok sayıda faktörle ilişkilidir. Dolayısıyla, okuldan işe geçiş süreci çok sayıda yapıyı kapsamaktadır. Her yapının sorunda veya çözümde katkısı bulunmaktadır. Tüm sorunların bireyde düğümlendiğini varsayan bireyselci yaklaşım bir taraftan bireyi değersizleştirir ve sürekli baskı altında tutarken diğer taraftan yapısal sorunların varlıklarını sürdürmesine de imkân tanımaktadır. Sonuç olarak her ülkenin dinamikleri farklı olsa da sorunlar ancak yapısal bir yaklaşımla çözülebilir hale gelmektedir.

Okuldan işe geçişte çoğu problemin eğitimden ziyade iş piyasasından kaynaklandığı görülmektedir. Bir ülkede ekonomi daralıyorsa ve iş piyasasında yeterli iş pozisyonu yoksa eğitimden işe geçiş doğal olarak sorunlu olacak, ancak bu sorun tek başına eğitimin sorumluluğu olmayacaktır. Aslında iş piyasası uzayını ihmal eden yaklaşım dolaylı olarak, geçiş mekanizmalarına yapısal ve sistematik bakışa sahip olmayı da engellemektedir. Geçiş alanının çok kapsamlı mekanizmalara sahip olduğu kabul edilmediğinde, bu durumda soruna yapısalcı bakış yerine bireyselci bakış ile yaklaşılmaktadır. Yani, bu durumda sorunlar sistem ile değil bireylerin kendi başarısızlıkları ile ilişkilendirilmektedir. Böylece, bireyler kendilerine odaklanmakta ve yetkinlik ve becerilerini artırmak için tüm sorumluluğu üzerine almakta, geçiş sisteminin zorlukları ile tek başlarına mücadeleye zorlanmaktadır. Diğer taraftan okuldan işe geçişte yapılardan kaynaklanan sorunlar da çözülememektedir. Dolayısıyla kitap, aslında okuldan işe geçiş sorununa özellikle bütünsel yaklaşmanın önemine yaptığı vurgu nedeniyle sorunları farklı boyutları ile görebilme imkânı vermektedir. Ayrıca, kitabın bir bütün olarak ülkemizde mesleki eğitimde okuldan işe geçiş sorunlarının arkaplanlarını görebilmeye katkı sağlama potansiyeli oldukça yüksektir.

Son olarak, gençlerin sorunlarını insani bir sorun olarak kabul edip iyileştirmenin ötesine geçerek, ekonomideki önemi veya oluşturduğu yük nedeniyle gençlerin dışlanmalarının topluma ekonomik maliyetinin öne çıkartılması (Ministry of Employment and Economy, 2012), bu maliyeti düşürmek için farklı yöntemler aracılığıyla gençlerin ekonomiye kazandırılmaya çalışılması, insanın toplumdaki yerinin ne olduğunu görme açısından üzerinde ayrıca ve ayrıntılı düşünmeyi gerektirmektedir. Aynı yaklaşım mültecilerin entegrasyonuna yönelik yaklaşımda da kendisini göstermektedir (Masoud ve diğ., 2020). Entegrasyon, toplumda çok boyutlu katılım ile ilgili yapılacakları içermesine rağmen, sadece iş piyasasına katılım ile ilişkilendirilmesi (FMEE, 2016; Masoud ve diğ., 2020; MEAE, 2016; Saukkonen, 2017), dolayısiyla istihdamın entegrasyonun başarılı olduğunu ölçen tek gösterge olarak kullanılması yine insanı mekanik bir ekonomik nesne olarak görme ve sorunları bireysel bağlama indirgeme yaklaşımın ürünüdür. Oysa entegrasyonun ötesinde eğitimden işe geçiş çok boyutlu toplumsal bir sorun alanını oluşturmakta, dolayısıyla istihdamın ötesinde sorunlara yönelik insani çözümler geliştirmeyi hak etmektedir. Tabi ki bu aşamaya geçebilmek için sorunu öncelikle bu bağlamda değerlendirebilmek gerekmektedir. 


\section{Kaynaklar}

Arnardottir, J. R. (2020). Transition from School to Work: Icelandic Young People in NEET. Editörler: Brunila, K. ve Lundahl, L. Youth on the Move: Tendencies and Tensions in Youth Policies and Practices, (ss. 57-77), Helsinki: Helsinki University Press.

Ball, S. J. (2006). Education Policy and Social Class: Selected Works. London: Routledge.

Becker, G. S. (1962). Investment in Human Capital: A Theoretical Analysis. J Polit Econ, 70, 9-49.

Becker, G. S. (1964). Human Capital: A Theoretical and Empirical Analysis with Special Reference to Education. New York: Columbia University Press.

Bernardi, F. ve Ballarino, G. (2016). Education, Occupation and Social Origin: A Comparative Analysis of the Transmission of Socio-Economic Inequalities. Cheltenham: Edwarg Elgar.

Bertocchi, G. ve Spagat, M. (2004). The Evolution of Modern Educational Systems: Technical vs. General Education, Distributional Conflict, and Growth. J Dev Econ, 73, 559-582.

Bol, T. ve Van de Wefhorst, H. G. (2013a). The Measurement of Tracking, Vocational Orientation, and Standardization of Educational Systems: A Comparative Approach. GINI Discussion Paper 81:1-42.

Bol, T. ve Van de Wefhorst, H. G. (2013b). Educational Systems and the Trade-Off between Labor Market Allocation and Equality of Educational Opportunity. Comparative Educational Review, 57(2), 285-308.

Bourdieu, P. (1973). Cultural Reproduction and Social Reproduction. Editör: Brown, R. K. Knowledge, Educational and Cultural Change, (ss. 71-112), London: Tavistock.

Bourdieu, P. ve Passeron, J. C. (1990). Reproduction in Education, Society and Culture. London: Sage Publications.

Breen, R. (2005). Explaining Cross-National Variation in Youth Unemployment: Market and İnstitutional Factors. European Sociological Review, 21(2), 125-134.

Breen, R. (2010). Educational Expansion and Social Mobility in the 20th Century. Soc Forces, 89(2), 365-388. 
Breen, R. ve Jonsson, J. O. (2005). Inequality of Opportunity in Comparative Perspective: Recent Research on Educational Attainment and Social Mobility. Annu Rev Sociol, 31, 223-243.

Brunello, G. (2004). Stratified or Comprehensive? Some Economic Considerations on the Design of Secondary Education. CESifo DICE Report 4:7-10

Brunila, K. ve Lundahl, L. (2020a). Youth on the Move: Tendencies and Tensions in Youth Policies and Practices. Helsinki: Helsinki University Press.

Brunila, K. ve Lundahl, L. (2020b). Introduction. Editörler: Brunila, K. ve Lundahl, L. Youth on the Move: Tendencies and Tensions in Youth Policies and Practices, (ss.1-14), Helsinki: Helsinki University Press.

Casillas, A., Robbins, S., Allen, S. J., Kuo, Y. L., Hanson, M. A. ve Schmeiser, C. (2012). Predicting Early Academic Failure in High School from Prior Academic Achievement, Psychosocial Characteristics, and Behavior. Journal of Educational Psychology, 104(2), 407-420.

Commission of the European Communities (2005). Communication from the Commission to the Council on European Policies Concerning Youth: Addressing the Concerns of Young People in Europe-Implementing the European Youth Pact and Promoting Active Citizenship. Brussels, COM (2005) 206 final.

Darling-Hammond, L. (2010). The Flat World and Education: How America's Commitment to Future Equity Will Determine Our Future. New York, NY: Teachers College, Columbia University.

Diedrich, A. ve Sthyre, A. (2013). Constructing the Employable Immigrant: The Uses of Validation Practices in Sweden. Ephemera, 13(4), 759-783.

Finnish Ministry of Economic Affairs and Employment (2016). Government Integration Programme Outlines Areas of Focus for Integration in the Coming Years.

European Union Agency for Fundamental Rights (2017). Second European Union Minorities and Discrimination Survey: Main Results. Luxembourg: Publication Office of the European Union.

Granovetter, M. (1985). Economic Action and Social Structure: The Problem of Embeddedness. Am J Sociol, 91, 481-510.

Hodgson, A. ve Spours, K. (2020). Young People and Transitions in Upper Secondary Education in England: The Influence of Policy on the 'Local Opportunity Landscape'. Editörler: Brunila, K. ve Lundahl, L. Youth on the Move: Tendencies and Tensions in Youth Policies and Practices, (ss.127-147), Helsinki: Helsinki University Press. 
Irisdotter Aldenmyr, S. ve Olson, M. (2020). Ethical and Care-Oriented, but Still Psychological and 'At Risk': Teacher's Constructions of Young People's Transition from School to Society. Editörler: Brunila, K. ve Lundahl, L. Youth on the Move: Tendencies and Tensions in Youth Policies and Practices, (ss.164184), Helsinki: Helsinki University Press.

Jarvinen, T. (2020). Social Background and Labour Market Careers of Young People: A Comprasion of Two Cohorts of Finnish Young People not in Employment, Education or Training (NEET). Editörler: Brunila, K. ve Lundahl, L. Youth on the Move: Tendencies and Tensions in Youth Policies and Practices, (ss.37-56), Helsinki: Helsinki University Press.

Keskinen, S. (2016). From Welfare Nationalism to Welfare Chauvinism: Economic Rhetoric, the Welfare State and Changing Asylum Policies in Finland. Critical Social Policy, 36(3), 352-370.

Kurki, T., Masoud, A., Niemi, A. M. ve Brunila, K. (2018). Integration Becoming Business: Marketization of Integration Training for Immigrants. European Educational Research Journal, 17(2), 233-247.

Kuzgun, Y. (2000). Meslek Danışmanlığı: Kuramlar ve Uygulamalar. Ankara: Nobel Yayınlar1.

Kuzgun, Y. (2004). Meslek Rehberliği ve Danışmanlığına Giriş. Ankara: Nobel Yayınlar1.

Lindbal, M. ve Lundahl, L. (2020). Winding Paths through School and After: Young Swedes of Migrant Origin who Failed in Upper Secondary School. Editörler: Brunila, K. ve Lundahl, L. Youth on the Move: Tendencies and Tensions in Youth Policies and Practices, (ss.79-99), Helsinki: Helsinki University Press.

Lundahl, L. ve Olofsson, J. (2014). Guarded Transitions? Youth Trajectories and School-to-Work Transition Policies in Sweden. International Journal of Adolescence and Youth, 19(1), 19-34.

Lundahl, L. ve Lindblad, M. (2018). Immigrant Student Achievement and Education Policy in Sweden. Editörler: Volante, L., Klinger, D. ve Bilgili, Ö. Immigrant Student Achievement and Education Policy: Cross-Cultural Approaches, (ss. 6985), Dordrecht, The Netherlands: Springer.

Lundahl, L. ve Lindblad, M., Loven, A., Marald, G. ve Svedberg, G. (2017). No Particular Way to Go: Careers of Young Adults Lacking Upper Secondary Qualifications. Journal of Education and Work, 30(1), 39-52. 
Lundahl, L. ve Brunila, K. (2020). Epilogue: Silence and Challenges. Editörler: Brunila, K. ve Lundahl, L. Youth on the Move: Tendencies and Tensions in Youth Policies and Practices, (ss.185-190), Helsinki: Helsinki University Press.

Masoud, A., Kurki, T. ve Brunila, K. (2020). Learn Skills and Get Employed: Constituting the Employable Refugee Subjectivity through Integration Policies and Training Practices. Editörler: Brunila, K. ve Lundahl, L. Youth on the Move: Tendencies and Tensions in Youth Policies and Practices, (ss.101-123), Helsinki: Helsinki University Press.

Ministry of Economic Affairs and Employment in Finland (2016). Government Integration Programme for 2016-2019 and Government Resolution on a Government Integration Programme. Helsinki: Publications of the Ministry of Economic Affairs and Employment 47.

Ministry of Employment and Economy (2012). Youth Guarantee 2013. TEM Reports $8 / 2012$.

Moore, P. (2010). The International Political Economy of Work and Employability. New York: Palgrave Macmillan.

Myklebust, J. O. (2012). The Transition to Adulthood for Vulnerable Youth. Scandinavian Journal of Disability Research, 14(4), 358-374.

OECD (2018). International Migration Outlook 2018. Paris: OECD Publishing.

Ostergaard, L. B., Jensen, L. ve Pilegaard Jensen, T. (2014). Transitions in Secondary Education: Exploring Effects of Social Problems. Research in Social Stratification and Mobility, 38, 32-42.

Özer, M. (2018). The 2023 Education Vision and New Goals in Vocational and Technical Education. Journal of Higher Education and Science, 8(3), 425-435.

Özer, M. (2019a). Reconsidering the Fundamental Problems of Vocational Education and Training in Turkey and Proposed Solutions for Restructuring. Istanbul Üniversitesi Sosyoloji Dergisi, 39(2), 1-19.

Özer, M. (2019b). Background of Problems in Vocational Education and Training and its Road Map to Solution in Turkey's Education Vision 2023. Journal of Higher Education and Science, 9(1), 1-11.

Özer, M. ve Suna, H. E. (2019). Future of Vocational and Technical Education in Turkey: Solid Steps Taken after Education Vision 2023. Journal of Education and Humanities, 10(20), 165-192. 
Özer, M. ve Suna, H. E. (2020). The Linkage between Vocational Education and Labor Market in Turkey: Employability and Skill Mismatch. Kastamonu Education Journal, 28(2), 558-569.

Özer, M. (2020a). The Contribution of the Strengthened Capacity of Vocational Education and Training System in Turkey to the Fight against Covid-19. Journal of Higher Education, DOI:10.2399 /yod.20.726951.

Özer, M. (2020b). Türkiye'de Mesleki Eğitimde Paradigma Değişimi. Gazi Üniversitesi Gazi Ĕ̌itim Fakültesi Dergisi, DOI:10.17152/gefad.752523.

Özer, M. (2020c). Mesleki Eğitimde Okuldan İşe Geçişi Etkileyen Yeni Parametreler: Küresel Dönüşümünde Yeni Eğilimler. İnsan ve Toplum Dergisi.

Özer, M. (2020d). What Does PISA Tell Us about Performance of Education Systems? Bartın University Journal of Faculty of Education, 9(2), 217-228.

Özer, M. ve Perc, M. (2020). Dreams and Realities of School Tracking and Vocational Education. Palgrave Communications, 6, 34.

Quiroga, C. V., Janosz, M. Bisset, S. ve Morin, A. J. S. (2013). Early Adolescent Depression Symptoms and School Dropout: Mediating Processes Involving SelfReported Academic Competence and Achievement. Journal of Educational Psychology, 105(2), 552-560.

Reichelt, M., Collischon, M. ve Eberl, A. (2019) School Tracking and its Role in Social Reproduction: Reinforcing Educational Inheritance and the Direct Effects of Social Origin. The British Journal of Sociology, 70(4), 1-26.

Rosenbaum, J. E., Kariya, T., Settersten, R. ve Maier, T. (1990). Market and Network Theories of the Transition from High School to Work: Their Application to Industrialized Societies. Annu Rev Sociol, 16, 263-299.

Rönnlund, M. (2020). Young Citizenship: Academically High-Achieving Middle-Class Students in Transitions Talk about Participation. Editörler: Brunila, K. ve Lundahl, L. Youth on the Move: Tendencies and Tensions in Youth Policies and Practices, (ss.17-35), Helsinki: Helsinki University Press.

Rumberger, R. W. (2011). Dropping Out: Why Students Drop Out of High School and What Can Be Done About It. Cambridge, MA: Harvard University Press.

Saukkonen, P. (2017). Interplay and Co-operation between National and Local Levels in Integration Policy. Case Helsinki, Finland. Working Papers. Helsinki: City of Helsinki. 
Suna, H. E., Tanberkan, H., Eroğlu, E., Gür, B. S. ve Özer, M. (2020). The Causes of Field-of-Study Mismatch in Vocational and Technical Education in Turkey. Palgrave Communication.

Suna, H. E., Tanberkan, H. ve Özer, M. (2020). Changes in Literacy of Students in Turkey by Years and School Types: Performance of Students in PISA Applications. Journal of Measurement and Evaluation in Education and Psychology, 11(1), 76-97.

Suna, H. E., Tanberkan, H., Gür, B. S., Perc, M. ve Özer, M. (2020a). Socioeconomic Status and School Type as Predictors of Academic Achievement. Journal of Economy Culture and Society. DOI: doi.org/10.26650/JECS2020-0034.

Suna, H. E., Gür, B. S., Gelbal, S. ve Özer, M. (2020b). Science High School Students' Socioeconomic Background and Their Preferences regarding Their Transition into Higher Education. Journal of Higher Education, DOI:10.2399/yod.20.734921

Williams, A. (2009). Employability and International Migration: Theoretical Perspectives. Editör: McKay, S. Refugees, Recent Migrants and Employment: Challenging Barriers and Exploring Pathways, (ss.23-34), New York: Routledge.

Zucker, L. G. (1986). Production of Trust: Institutional Sources of Economic Structure, 1980-1920. Editörler: Staw, B. M. ve Cummings, L. L. Research in Organizational Behavior, (ss.53-112), Greenwich, Conn: JAI 
